\title{
A comparison of the effectiveness of word imagery and meaningfulness in paired-associate learning of nouns ${ }^{1}$
}

\author{
PADRIC C. SMYTHE AND ALLAN PAIVIO \\ UNIVERSITY OF WESTERN ONTARIO
}

Noun imagery (I) and meaningfulness $(m)$ were varied over an equivalent range in different paired-associate (PA) lists. In each list, one variable was systematically varied on stimulus and response sides within each of three different levels of the other variable. The results showed highly significant positive effects of $I$, more so on the stimulus than on the response side of pairs, these effects being qualified by a stimulus by response interaction. In contrast, $\underline{m}$ showed only a negative response effect attributable mainly to superior recall of low $\underline{m}$ responses when pair I was also low.

Numerous studies (see Goss \& Nodine, 1965) have indicated that meaningfulness (m; Noble, 1952) is highly effective in paired-associate (PA) learning. These studies have usually involved nonsense words as low $\mathrm{m}$ items, however, and at present there is considerable doubt about the effectiveness of $\underline{m}$ when varied only among famillar words. This conclusion arises from research concerned with the effect of noun imagery (I), a meaning variable defined (Paivio, 1965) in terms of a word's capacity to evoke nonverbal images. In contrast to $\mathrm{m}$, which usually has its greater effect on the response side of pairs, I is consistently more effective on the stimulus side, even when $\underline{m}$ is held constant (e.g., Paivio, Yuille, \& Smythe, 1966). Paivio \& Yuille (1967) varied I and m of noun pairs over an equivalent range in separate lists and found I to have a much greater effect than m. Paivio (1967) found that partialling out $\underline{m}$ had little effect on a positive relation between I and PA learning, whereas partialling out I reduced the effect of $\underline{m}$ to zero. Thus $\underline{m}$ is clearly less effective than $I$ and it may even be entirely ineffective when $I$ is controlled. The present study was undertaken as a more detalled comparison of the relative effects of $I$ and $m$ using new normative data on the variables. Nethod

Eight 12-pair PA lists were constructed using 40 nouns with Thorndike-Lorge (1944) frequencies ranging from 1 to 100 (AA), ${ }^{2}$ chosen from a pool of 925 nouns on which measures of $I$ and $m$ are avallable (Paivio, Yuille, \& Madigan, in press). Two basic lists were constructed so that one of the two variables (I or $\mathrm{m}$ ) was held constant within each pair of a list while high and low values of the other variable were systematically varied within the stimulus and response members. Three levels of the variable being held constant within pairs were employed in each 12-pair list. Thus one basic list had four pairs of High-I words, four pairs of Medium-I words, and four pairs of Low-I words. 3 Within each level of pair I, all combinations of High and Low $m$ occurred on the stimulus and response sides, i.e., High $\mathrm{m}$-High $\mathrm{m}$, High $\underline{m}-L o w ~ \underline{m}$, Low $\underline{m}-H i g h ~ \underline{m}$, and Low $\underline{m}-$ Low $\underline{m}$. The second basic list similarly included four pairs each that were High $\underline{m}$, Medium $\underline{m}$, and Low $\underline{m}$, and, within each level of pair $m$, I was systematically varied on the stimulus and response sides. Each list represented a 2 by 2 by 3 factorial design with Stimulus attribute, Response attribute, and Pair attribute as factors.

Two more lists were constructed by re-pairing members within each list, care being taken to preserve the original list design. Four additional lists resulted from "turning over" the pairs in each of the four lists already developed. Thus, four different pairs represented each combination of item attributes employed in the list design. The four lists in which m was held constant within pairs are referred to as the A series and those lists in which I was held constant within pairs comprise the B series.

The following figures represent the means for High, Medium, and Low $I$ and $\underline{m}$ values of the 40 nouns used in the present study: High I, 6.47; Medium I, 4.62; Low I, 2.94; High $\underline{m}, 7.06$; Medium $\mathrm{m}, 5.52$; Low $\underline{m}, 4.80$. Imagery and $\underline{m}$ were varied equally in terms of standard score units (range $=1.83$ and 1.87 , respectively).

Eighty students (55 male, 25 female) from introductory psychology courses served as Ss. Ten Ss learned one of each of the eight lists in an individual testing session. Lists were presented in four alternating study-recall blocks by means of a memory drum at a 3 sec rate for both study and recall trials. Three practice pairs were presented on flash cards prior to the experiment. Ss read all pairs aloud and responded orally on test trials.

Resulfs

Series A and B were analyzed separately but the results for the four lists within either series were pooled for their respective analyses. A three-way analysis of variance (all repeated measures) was performed on the mean total recall scores over four trials, with two levels each of the stimulus and of the response attribute, and three levels of the pair attribute, as factors.

Effects of Stimulus and Response I at three levels of pair $\underline{m}$. The mean total recall for each cell of the A series is presented in Table 1 . The analysis showed 
Table 1

Mean total correct recall over four trials for High, Medium, and Low $m$ pairs as a function of stimulus and response $I(N=40)$ PAIRS

\begin{tabular}{llll} 
& High $\underline{\mathbf{m}}$ & Medium $\underline{\mathbf{m}}$ & Low $\underline{\mathbf{m}}$ \\
\hline Stimulus-Response & & & \\
\hline High I-High I & 2.650 & 3.025 & 3.100 \\
High I-Low I & 2.400 & 1.800 & 2.325 \\
Low I-High I & 2.025 & 1.900 & 1.700 \\
Low I-Low I & 1.875 & 1.900 & 1.975 \\
\hline
\end{tabular}

Note: Sd range $=1.16-1.48$

that recall was better for pairs with High rather than low I stimuli $(F=19.719, \mathrm{df}=1 / 39, \mathrm{p} .01)$ and responses $(F=11.175, \mathrm{df}=1 / 39, \mathrm{p}<.01)$. A significant interaction between Stimulus $I$ and Response I ( $F$ $=10.765, \mathrm{df}=1 / 39, \mathrm{p}<.01$ ) indicates that the positive effect of Stimulus I was greater when Response I was high than when Response I was low; conversely, Response I had a positive effect when Stimulus I was high but had no effect when Stimulus I was low. The pair $m$ level had no effect $(F=0.605$, $d f=2 / 78)$, nor did it interact significantly with the other variables.

Effects of Stimulus and Response $\underline{m}$ at three levels of pair l. Mean total recall scores for each cell of the $B$ series are presented in Table 2. With $\mathrm{df}=1 / 39$ in each case, the Fs were 0.020 and $3.717(p<.05)$ for Stimulus $\underline{m}$ and Response $\underline{m}$, respectively. Inspection of Table 2 reveals that the main effect of Response $\underline{m}$ is a negative one. The effect of Pair I was highly significant $(F=45.929, \mathrm{df}=2 / 78, \mathrm{p}<.01$ ) and Pair I interacted significantly with Stimulus $\underline{m}$ $(F=5.491, \mathrm{df}=2 / 78, \mathrm{p}<.01)$ and with Response $\underline{m}$ $(F=3.664$, df $=2 / 78, p<.05)$. The large main effect of Pair I is due to the superiority of recall of High I pairs over both Medium and Low I pairs. Neither of the interactions suggest any substantial qualification of the main effect of Pair I, but they do indicate that the negative main effect of Response $\underline{m}$ is due mainly to superior recall of Low $m$ responses for pairs that were also Low I.

\section{Discussion}

The positive main effects of I and the interaction of Stimulus and Response term I are consistent with earlier findings (e.g., Paivio et al, 1966). The hypothesis that stimulus-evoked imagery is particularly crucial (Paivio, 1965) was also supported in that recall was better for High I-Low I than Low I-High I pairs $(t=1.94, d f=39, p<.05$, one-tailed hypothesis $)$.

The effects of $m$ in PA learning are often linked to verbal mediation processes, as in Underwood \& Schulz' (1960) associative probability hypothesis and its corollary, the interference paradox. According to such a view, the small negative effect of response $\underline{m}$, occurring in the present study when list I was low, may reflect competition among verbal mediators, which would be expected particularly at relatively fast presentation rates (Barnes \& Schulz, 1966). Ob-
Table 2

Mean total correct recall over four trials for High, Medium, and Low I pairs as a function of stimulus and response $m(N=40)$

\begin{tabular}{llll} 
& \multicolumn{3}{c}{ PAIRS } \\
\cline { 2 - 4 } Stimulus-Response & High I & Medium I & Low I \\
\hline High $\underline{\mathrm{m}}$-High $\underline{\mathrm{m}}$ & 3.325 & 2.475 & 1.800 \\
High $\underline{\mathrm{m}}$-Low $\frac{\mathrm{m}}{\mathrm{m}}$ & 2.875 & 2.375 & 2.525 \\
Low $\underline{\mathrm{m}}$-High $\frac{\mathrm{m}}{\mathrm{m}}$ & 3.425 & 1.725 & 2.075 \\
Low $\underline{\mathrm{m}}$-Low $\underline{\mathrm{m}}$ & 3.575 & 2.175 & 2.500 \\
\hline
\end{tabular}

Note: Sd range $=.65-1.47$

viously the problem requires further research, however, using larger samples of items varying in $\underline{m}$.

These and earlier related findings (e.g., Paivio, 1967) have important general implications. Because of the positive correlation between $I$ and $\underline{m}(r=+.72$ for 925 nouns; Paivio et al, in press), the two are likely to be confounded in studies involving nouns as items (e.g., Saltz, 1967) and the present results suggest that the effective underlying variable could be nonverbal imagery rather than the verbal associations presumably indexed by $\underline{\mathrm{m}}$.

\section{References}

BARNES, L. D., \& SCHULZ, R. W. Meaningfulness and the associative phase of paired-associate learning. Paper presented at M.P.A. Convention, 1966.

GOSS, A. E., \& NODINE, C. F. Paired-associates learning. New York: Academic Press, 1965.

NOBLE, C. E. An analysis of meaning. Psychol. Rev., 1952, 59, 421-430.

PAIVIO, A. Abstractness, imagery, and meaningfulness in pairedassociate learning. J. verbal Learn. verbal Behav., 1965, 4, 32-38.

PAIVIO, A. Paired-associate learning and free recall of nouns as a function of concreteness, specificity, imagery, and meaningfulness. Psychol. Rep., 1967, 20, 239-245.

PAIVO, A. A factor-analytic study of word attributes and verbal learning. J. verbal Learn. verbal Behav., in press.

PAIVIO, A., \& YUILLE, J. C. Mediation instructions and word attributes in paired-associate learning. Psychon. Sci, 1967, 8, 65-66.

PAIVIO, A., YUILLE, J. C., \& MADIGAN, S. Concreteness, imagery, and meaningfulness values for 925 nouns. $J$. exp. PsychoL, Monogr. Suppl, in press.

PAIVIO, A., YUILLE, J. C., \& SMYTHE, P. C. Stimulus and response abstractness, imagery, and meaningfulness, and reported mediators in paired-associate learning. Canad. J. Psychol, 1966, 20, 362-377.

SALTZ, E. Thorndike-Lorge frequency and $m$ of stimuli as separate factors in paired-associates learning. $J$. exp. Psychol, 1967,73 , 473-478.

THORNDIKE, E. L., \& LORGE, I. The teachers' word book of 30,000 words. New York: Bureau of Publications, Teachers' College, Columbia University, 1944.

UNDERWOOD, B. J., \& SCHULZ, R. W. Meaningfulness and verbal learning. Philadelphia: Lippincott, 1960.

Notes

1. This research was supported by grants to the second author from the National Research Council of Canada (Grant APA-87) and from the University of Western Ontario Research Fund.

2. Previous research (Paivio et al, 1966) showed that frequency cannot account for the effects of $I$ and $m$, and it was not controlled here. A correlational analysis of the present learning data showed that ThorndikeLorge frequency of stimulus and response terms correlated -.03 and .12 , respectively, with mean recall scores for the pairs.

3. Imagery and rated concreteness (c) which correlate .83 in the word pool (Paivio et al, in press), were allowed to covary. 